\title{
The Physical OCEanography OF THE AMAZON OUTFLOW
}

\author{
By W. Rockwell Geyer, Robert C. Beardsley, \\ Julio Candela, Belmiro M. Castro, \\ Richard V. Legeckis, Steven J. Lentz, \\ Richard Limeburner, Luis B. Miranda \\ and John $\mathrm{H}$. Trowbridge
}

T HE AMAZON shelf is an unusually energetic coastal region. The Amazon River discharges between 80,000 and $250,000 \mathrm{~m}^{3} \mathrm{~s}^{-1}$ of fresh water onto the shelf at the equator (Oltman, 1968; Muller-Karger et al., 1988). The resulting surface plume of brackish water extends hundreds of kilometers seaward and northwestward along the coast (e.g., Gibbs, 1970; Milliman et al., 1975; Curtin, 1986a). The North Brazil Current sweeps the waters over the outer shelf and slope northwestward at speeds reaching 1-2 $\mathrm{m} \mathrm{s}^{-1}$ (Flagg et al.. 1986; Richardson and Reverdin, 1987). Previous current measurements on the shelf indicate across-shelf tidal velocities of 1-2 $\mathrm{m} \mathrm{s}^{-1}$ (Gibbs, 1982; Curtin, 1986b). The persistent trade winds impose a cross-shelf wind stress as large as 1 dyn $\mathrm{cm}^{-2}$ (Picaut et al., 1985). The Amazon River discharge, the North Brazil Current transport, and the trade winds all exhibit strong seasonal cycles (see Figure 3, Nittrouer et al., this issue a). These energetic and highly variable forcing functions result in considerable variability in the hydrographic structure and currents on the Amazon shelf, which in turn lead to marked variations in the transport and fate of sediments and waterborne material. The tremendous flux of suspended sediment is regulated by the structure and energetics of the flow; hence the distribution and deposition of sediments as well as particle-reactive chemicals are intrinsically coupled to the physical oceanographic regime.

\section{The AmasSeds Physical Oceanography Program}

As part of A Multidisciplinary Amazon Shelf SEDiment Study (AmasSeds), a physical oceanography observational program was conducted to better understand the characteristics and dynam-

W.R. Geyer, R.C. Beardsley, J. Candela, S.J. Lentz, R. Limeburner, Woods Hole Oceanographic Institution, Woods Hole, MA 02543 USA. B.M. Castro, L.B. Miranda. Universidade de São Paulo, Instituto Oceanográfico, Butanta CEP 05508, São Paulo, Brasil. R.V. Legeckis. NOAA/NESDIS. Code E/RA 13, Washington, DC 20233 USA. ics of water properties and currents over the Amazon shelf. This measurement program included a variety of observational approaches in order to study different aspects of the physical regime (Fig. 1). Three large-scale, shipboard hydrographic and acoustic Doppler current profiler (ADCP) surveys were conducted at different stages of river discharge to map the spatial distribution of water properties and the current structure through the annual cycle. To complete the seasonal picture a fourth cruise is planned for November, 1991. Surface drifters were released during each of the hydrographic cruises to provide a Lagrangian perspective of the shelf circulation. Satellite images were collected to determine the spatial variability associated with the river plume and to aid in the interpretation of shipboard, drifter, and moored observations. A moored array of current meters was deployed across the shelf about $200 \mathrm{~km}$ north of the river mouth for a period of about 5 months to determine the temporal characteristics of the current, salinity and water temperature and to investigate the relationship between current and salinity variability and the Amazon River discharge, the North Brazil Current, the trade winds, and the tides. A sequence of detailed shipboard measurements of water properties and currents within the plume was conducted to investigate the mechanisms responsible for cross-front exchange of salt and sediment. This observational program has provided the most comprehensive set of physical oceanographic measurements to date of the structure and variability of the Amazon plume and the Amazon shelf circulation.

Preliminary analysis of these measurements has revealed a remarkable amount of current and salinity variability on time scales of days to weeks, consistent with the observations of Curtin and Legeckis (1986) and Curtin (1986a; 1986b). These relatively rapid changes in the physical characteristics of the plume are apparently as large or larger than the seasonal variations, which were expected to dominate the hydrographic and subtidal current 


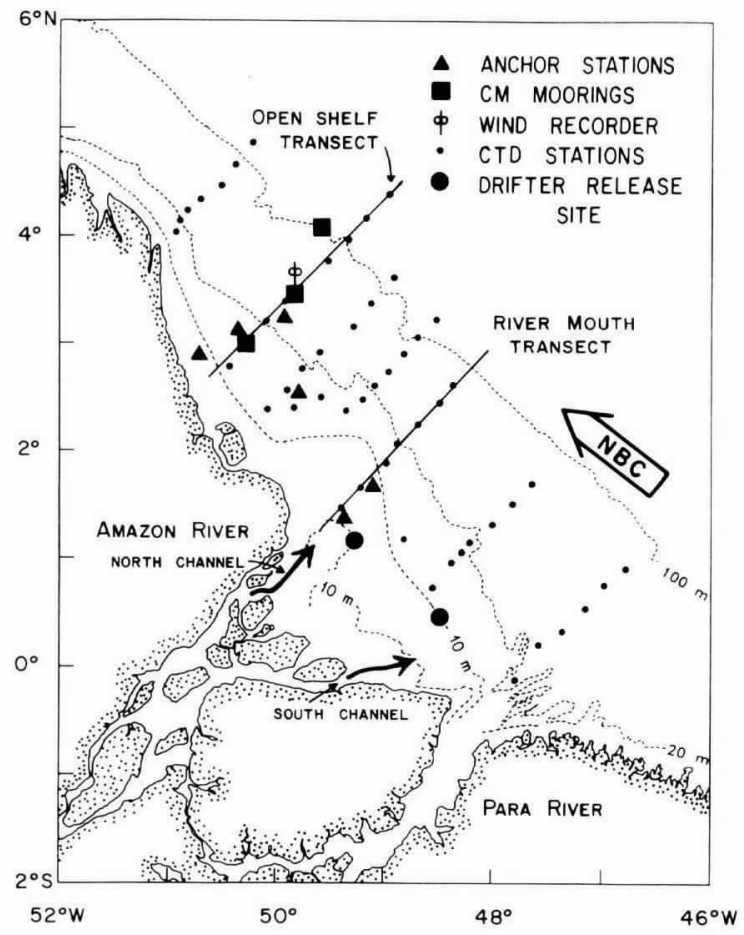

Fig. 1: Map of the Amazon shelf showing locations of the shipboard and moored measurements made as part of the physical oceanography program of AmasSeds. Three regional-scale hydrographic and water chemistry surveys have been made to map the structure of the Amazon River freshwater discharge over the shelf during different stages of the river discharge cycle (Surveys were conducted in August 1989, FebruaryMarch 1990, and May-June 1990, corresponding to falling, rising, and maximum river discharge, and a fourth survey is planned for November 1991 during minimum discharge). These surveys included CTD and ADCP profiling along seven cross-shelf transects and took 6-8 days to complete. The CTD station locations for the March 1990 survey are shown here; a similar sampling pattern was used for the other surveys. To examine Lagrangian residence times in the Amazon plume, one or two satellite-tracked drifters drogued at $5 \mathrm{~m}$ were deployed near the river mouth during each survey; shown here are the release sites for the two drifters deployed during the March 1990 survey. To examine temporal variability, instruments were deployed during February-June 1990 at three mooring sites along the Open-Shelf Transect to obtain time series of current, temperature, salinity, and wind. Twelve to twenty-six hour time-series measurements of temperature, salinity, current and suspended-sediment concentration were collected at anchor stations to study frontal processes and tidal and higher frequency variability. The North Brazil Current (NBC) flows northwestward along the continental margin. The river discharge occurs via the North and South Channels of the Amazon, with the North Channel carrying most of the discharge. data based on the strong seasonal fluctuations of the forcing variables (Nittrouer et al., this issue a, Figure 3 ). These short time-scale variations may have important implications on how and where the fresh water, sediment, and chemicals originating from the Amazon River are dispersed. This variability also influences interpretation of hydrographic surveys and station data taken in the region, as pointed out by Curtin (1986b). The analysis phase of AmasSeds is just beginning, so at present only speculation is possible regarding the dynamical origins of the current and salinity variability, and on the implications of recent findings about the distributions of sediments and geochemical species. There are, however, enough interesting new discoveries that an initial description of physical processes on the Amazon shelf is warranted at this time.

\section{Observational Results}

The hydrography of the Amazon shelf is dominated by a surface plume of brackish water formed as the fresh Amazon River water mixes with the high-salinity ocean water. Directly offshore of the river mouth the salinity structure resembles an estuarine salt wedge (Fig. 2); in crosssection, it is comparable to much smaller salt wedges such as the Mississippi (Wright, 1970) and the Fraser (Geyer and Farmer, 1988). The principal difference is in the transverse dimension, which is orders of magnitude larger in the case of the Amazon, because the salt wedge occurs well seaward of the mouth and is not laterally confined to a river channel, as in smaller salt-wedge estuaries. The tidally averaged cross-shelf flow is also comparable in structure and magnitude to other salt-wedge regimes, with landward flow of 0.05

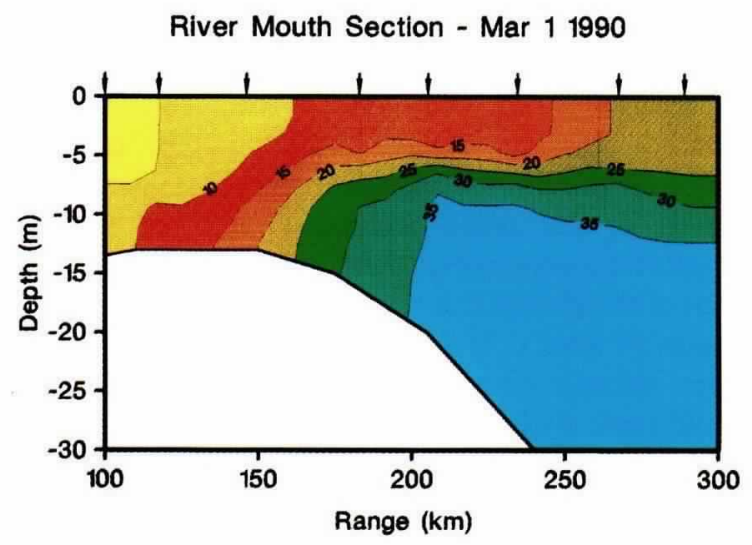

Fig. 2: Vertical salinity section made along the River-Mouth transect on March 1, 1990, at spring tide. The CTD station locations are denoted by vertical arrows along ocean surface. The RiverMouth Transect (see Fig. 1) starts in the North Channel of the Amazon River and extends across the shelf to the shelf break. The horizontal range is relative to the mouth of the North Channel. Note the large horizontal extent and large vertical salinity gradients in the river-mouth salt wedge.
The principal

difference is in the transverse dimension, which is orders of magnitude larger . . . 
Surface Sallnity - Feb 28 - Mar 71990

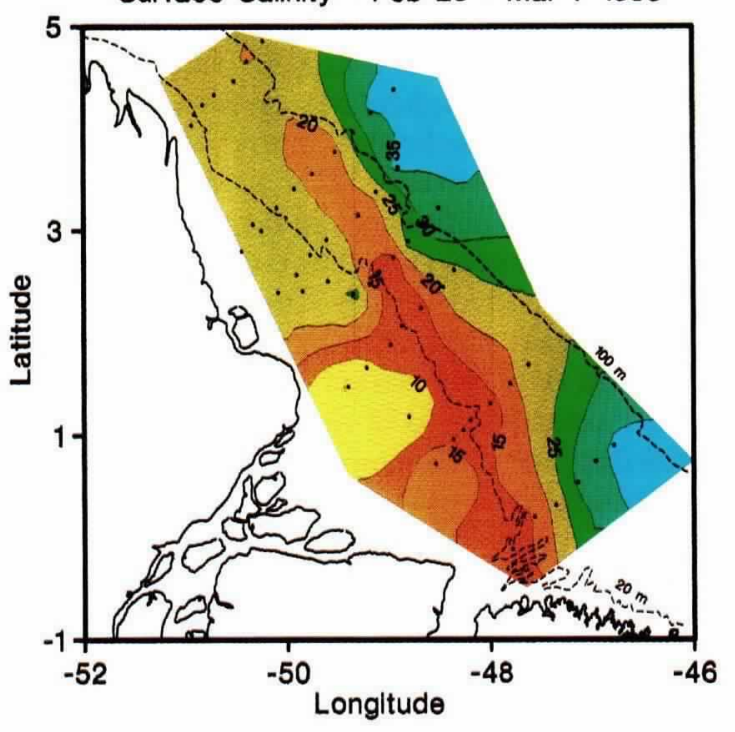

Surface Sallnity - May 22-30 1990

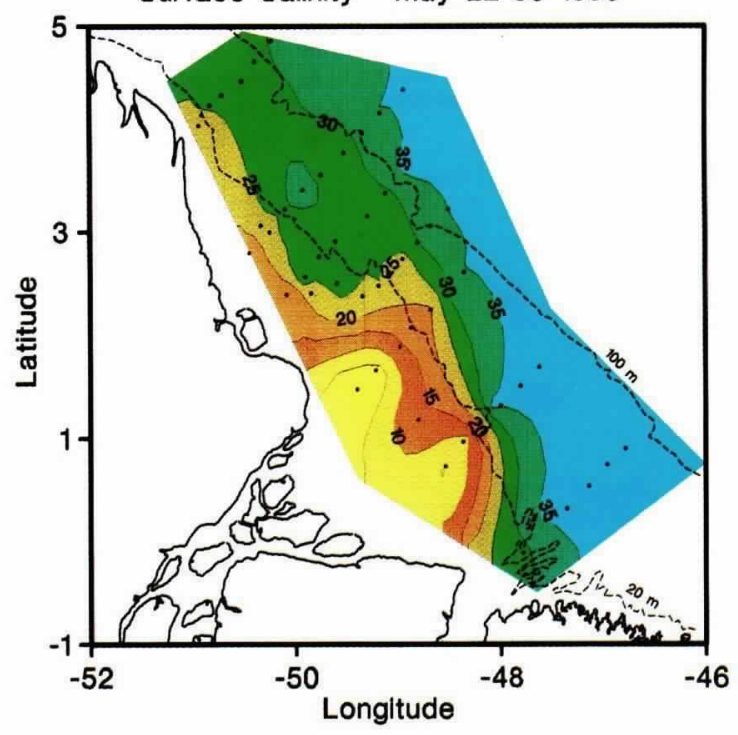

Fig. 3: Surface salinity distributions observed during a) Feb 28-March 7, 1990 and b) May 22-30, 1990. The black dots represent hydrographic stations and the same color code for salinity is used in each panel. Note the well-developed plume extending northwestward over the mid and outer shelf in March (during rising river discharge) and the much smaller and less fresh plume in June (during maximum river discharge).

... maximum currents

over the inner shelf

reaching $2 \mathrm{~m} \mathrm{~s}^{-1}$

during spring tides . . .
$0.10 \mathrm{~m} \mathrm{~s}^{-1}$ within the wedge and seaward flow of $0.4-1.0 \mathrm{~m} \mathrm{~s}^{-1}$ in the overlying brackish plume. Unlike most smaller salt wedges, however, there is also a component of flow parallel to the front (roughly along-shelf) that is presumably associated with the larger scale shelf circulation. Because the Amazon River mouth is so close to the Equator $\left(1^{\circ} \mathrm{N}\right)$, rotational effects are weak relative to bottom friction; rotation only begins to become important in the outflow plume several hundred $\mathrm{km}$ to the north, near the latitude of the North Brazil Current retroflection (Richardson and Reverdin, 1987).

Away from the river mouth, the surface plume extends northwestward along the shelf, as indicated in previous investigations. While it always heads in the same direction, repeated hydrographic surveys indicate that the structure and extent of the plume can vary substantially over time scales of weeks. To illustrate this variability, surface salinity distributions observed during the large-scale hydrographic surveys in March 1990 and May 1990 are shown in Figure 3 and a sequence of salinity sections across the Open-Shelf transect are shown in Figure 4. During rising river discharge in March, the surface plume has a welldefined tongue of water less than $20 \%$ extending at least $300 \mathrm{~km}$ northwestward over the middle and outer shelf, while during maximum river discharge in May, the surface plume is smaller and more confined near the coast. Along the OpenShelf transect (Fig. 4), the plume structure varies between a wedge-like region confined near the coast (February 1990) and an offshore surface tongue characterized by a mid-shelf salinity min- imum (March 1990). These salinity variations represent order one changes in the total freshwater content of the shelf on time scales much shorter than the seasonal changes in river discharge. In contrast, the near-bottom salinity shows a more stationary and spatially uniform distribution, with high-salinity water extending beneath the plume shoreward as far as the $20-\mathrm{m}$ isobath along most of the shelf.

Currents on the Amazon shelf are dominated by two principal components, a cross-isobath, barotropic, semidiurnal tidal flow, and an alongisobath, vertically sheared, subtidal flow directed northwestward along the shelf. Moored measurements indicate that the semidiurnal tidal currents have a pronounced spring-neap variation, with maximum currents over the inner shelf reaching $2 \mathrm{~m} \mathrm{~s}^{-1}$ during spring tides and only $0.7 \mathrm{~m} \mathrm{~s}^{-1}$ during neap tides. Over the shelf north of Cabo Norte (the headland to the north of the river mouth), the small phase variations of tidal currents and surface elevation across the shelf suggest the semidiurnal tide in this region is a strongly damped standing wave, which approaches resonance near $2^{\circ} \mathrm{N}$ as the shelf widens southward (Fig. 5). To the south of Cabo Norte, the phase of the tidal currents and surface elevation increase significantly in the shoreward direction, indicating a more progressive tidal wave, with a large fraction of the incident tidal energy dissipated within the river mouth.

The subtidal currents are strongly sheared, with very strong northwestward (along-shelf) near-surface currents that reach speeds in excess of $1.5 \mathrm{~m}$ $\mathrm{s}^{-1}$, based on moored data from the Open-Shelf 

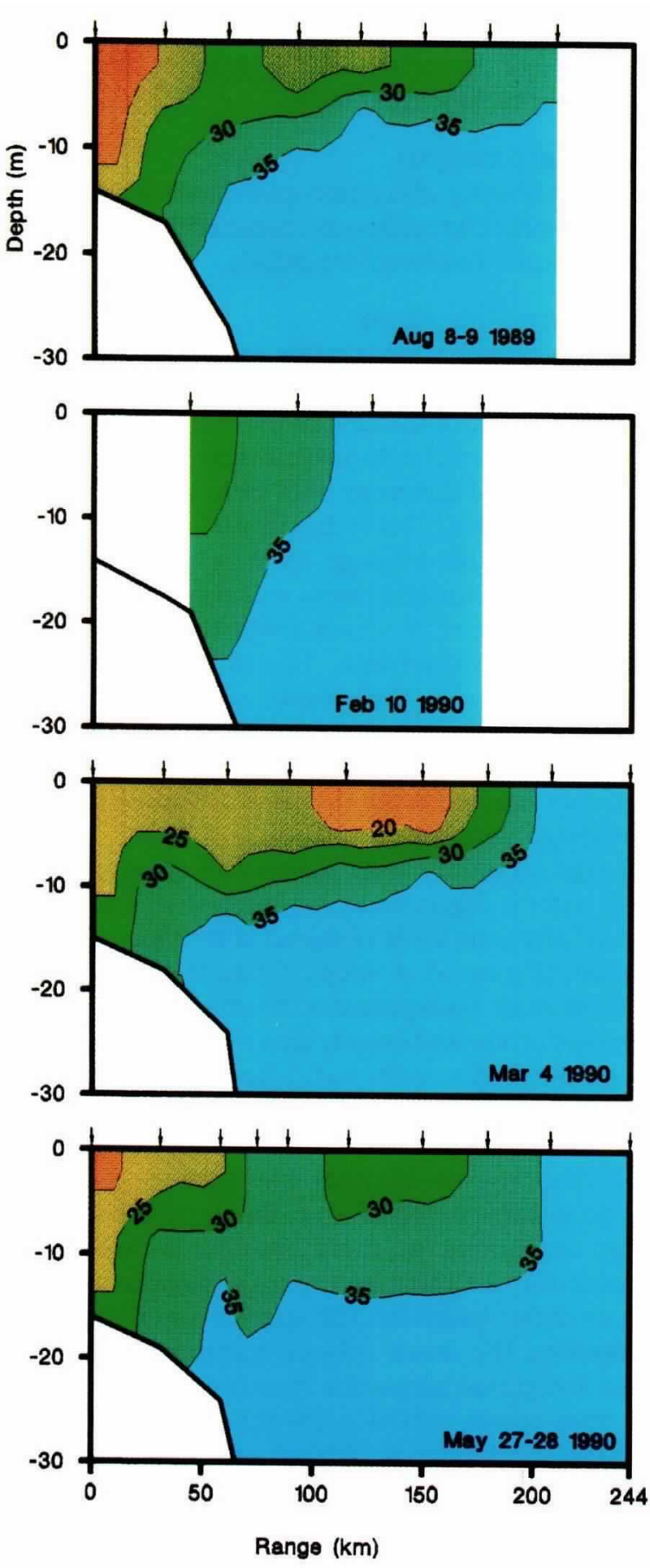

Fig. 4: A sequence of vertical sections of salinity made along the Open-Shelf Transect during a) August 89, 1989, b) February 10, 1990, c) March 4, 1990, and d) May 27-28, 1990. CTD station locations are denoted by vertical arrows at ocean surface. The color code for salinity is identical to that used in Figure 3, and only the upper $30 \mathrm{~m}$ is shown because the deeper water varies little from $36.2 \%$. Note the variations in the structure of the plume from a nearshore wedge (February 1990) to a tongue characterized by an offshore salinity minimum (March 1990).

transect. Elsewhere on the shelf, analysis of the anchor-station profile data also indicates strong but variable northwestward subtidal flow in the surface waters, except in the vicinity of the saltwedge front where the flow has a significant offshore component. In contrast to the energetic near-surface currents, the near-bottom, subtidal flow is weak, with typical speeds of $0-0.2 \mathrm{~m} \mathrm{~s}^{-1}$.

The time series data obtained at the Open-Shelf moorings show large fluctuations in the near-surface, subtidal currents; the along-shelf (northwestward) component varies from -0.5 to $1.5 \mathrm{~m}$ $\mathrm{s}^{-1}$ with a characteristic time scale of days to weeks (Fig. 6). The near-surface, along-shelf currents at these sites are positively correlated with each other (correlation coefficient 0.79). However these nearsurface currents are not significantly correlated with deeper flow at either site. The outer shelf mooring, apparently located within the North Brazil Current, also shows large along-shelf current fluctuations $(-0.2$ to $1.3 \mathrm{~m} / \mathrm{s})$, although these variations are uncorrelated with the current fluctuations at the shallower moorings.

The moored salinity measurements are particularly striking in their variability; the near-surface salinity varies between 10 and $27 \%$ at the innershelf site and between 15 and $36 \%$ at the midshelf site during the period mid-February to midApril (Fig. 6). The deeper moored salinity measurements made beneath the plume at mid-shelf varies little from $36 \%$, indicating the relatively constant value of salinity in the subsurface waters of the North Brazil Current. These near-surface variations in the moored salinity measurements are consistent with variations in total freshwater content over the shelf, estimated from the shipboard hydrographic surveys. The characteristic time scale of the near-surface moored salinity variability is similar to that of the along-shelf velocity, although the correlations between nearsurface, along-shelf velocity and salinity are not significant at the $95 \%$ level. The salinity time series also includes a trend toward fresher water over the deployment period, which is qualitatively consistent with the expected increasing river discharge during this period.

The strong tidal currents probably dominate the energetics of the bottom boundary layer, controlling the magnitude of the bottom stress and the resuspension of sediment (see Kineke et al., this issue). The stratification associated with the freshwater plume is generally far enough above the bottom over most of the shelf that salt stratification does not inhibit bottom turbulence; however the stratification due to suspended sediment becomes very large over some portions of the Amazon shelf, with suspended concentrations of $10-100 \mathrm{gm} \mathrm{l}^{-1}$ (fluid mud) in the bottom 1-3 $m$ of the water column. Under these conditions, the velocity shears in the bottom meter of the water column are large, but the suspended sediment stratification is often strong enough to suppress turbulence, based on estimates of the gradient Richardson number (Ri) that frequently indicate $\mathrm{Ri}>0.25$. Higher in the water column, salinity
... strong but variable

northwestward subtidal flow in the surface waters ... 




Fig. 5: Map of the North Brazil shelf showing a) the amplitude in meters of the semidiurnal constituent $M_{2}$ (12.42 hour period) surface tide (dashed contours) and b) the amplitude in meters per second (vectors) and phase in degrees of the depth-averaged $M_{2}$ velocity. The surface tide contours are based on bottom pressure measurements (E.G.\&G., 1981; AmasSeds Sediment-Transport Group), the empirical analysis of Schwiderski (1979), and coastal sea-level observations (NOAA, 1973). The $M_{2}$ currents are rectilinear, and the amplitude at flood and ebb is shown as a vector. with the magnitude scale in the upper right. The $M_{2}$ phase difference between the onshore tidal current at flood and the surface tide at maximum elevation over the continental slope is shown. Note that the relative phase difference for an inviscid standing wave is $-90^{\circ}$, while that for an inviscid progressive wave is $0^{\circ}$. Also, note the large increase in surface tide and relatively small negative phase difference over the shelf north of Cabo Norte. South of Cabo Norte, where the cross-shelf phase variation is more suggestive of a progressive wave, less is known about the surface tide, hence the large question mark in the mouth of the Amazon River.

dominates the stratification, and the velocity shears are generally associated with the mean along-shelf flow rather than the cross-shelf tidal flow. Based on velocity and salinity profile data obtained at anchor stations, the estimates of $\mathrm{Ri}$ indicate generally stable conditions $(\mathrm{Ri} \approx 1$ ) within the plume, but unstable conditions ( $R \mathrm{i}$ $<0.25$ ) frequently occur in the vicinity of the salt wedge front and intermittently occur elsewhere. Not surprisingly, vertical mixing is most intense during spring tides, and both the salinity structure and suspended sediment distributions appear to vary through the spring-neap cycle in response to changes in turbulent intensity.

\section{Preliminary Analysis}

The following discussion represents work-inprogress aimed at addressing some of the striking observational results of AmasSeds.

\section{Variability of the Plume}

In typical estuarine systems, large fluctuations in salinity are directly related to fluctuations in river discharge. In the case of the Amazon River, however, historical data suggest there is a smooth annual cycle of discharge with little variation on short time scales. This is due in part to the enormous size of the drainage basin, which encompasses several climatic zones, and also to the large volume of the river which tends to filter rapid fluctuations in discharge. Therefore, the shortterm variations in the salinity structure of the plume over the shelf are not due to fluctuations in river discharge, but rather to processes on the shelf that may alter the rate at which the plume is advected away from the mouth.

Large variability in the along-shelf transport of fresh water is suggested by the along-shelf velocity and salinity time series obtained at the Open Shelf transect (Figure 6). A rough estimate of the rate of freshwater transport can be made from the moored current and salinity data by assuming that the salinity and velocity vary smoothly across the shelf, that most of the freshwater transport occurs shoreward of the $60 \mathrm{~m}$ isobath (where the midshelf mooring was located), and that the plume has an average depth of $7 \mathrm{~m}$. Based on the shipboard measurements, these assumptions are reasonable for obtaining an order-of-magnitude estimate of the freshwater transport. From these assumptions, the mean volume transport of fresh water integrated across the Amazon shelf during the deployment period is $180,000 \mathrm{~m}^{3} \mathrm{~s}^{-1}$ with a standard deviation of $140,000 \mathrm{~m}^{3} \mathrm{~s}^{-1}$ ! The estimated mean transport of fresh water is consistent with other estimates of the Amazon discharge which range from 100,000 to $200,000 \mathrm{~m}^{3} \mathrm{~s}^{-1}$ during this season (Oltman, 1968; Muller-Karger et al., 1988). However, the amount of freshwater leaving the Amazon shelf to the northwest is apparently fluctuating by an amount nearly equal to the river discharge itself. If the outflow of freshwater from the river shelf has this amount of shortterm variability but the inflow from the river is relatively constant, it follows that there should be correspondingly large fluctuations in the freshwater content of the Amazon plume over the shelf, which is confirmed by the hydrographic survey data.

\section{Dynamics of the Along-Shelf Flow}

The causes of the large along-shelf current variations seen in Figure 6 still remain to be determined. Several possibilities exist: the North 


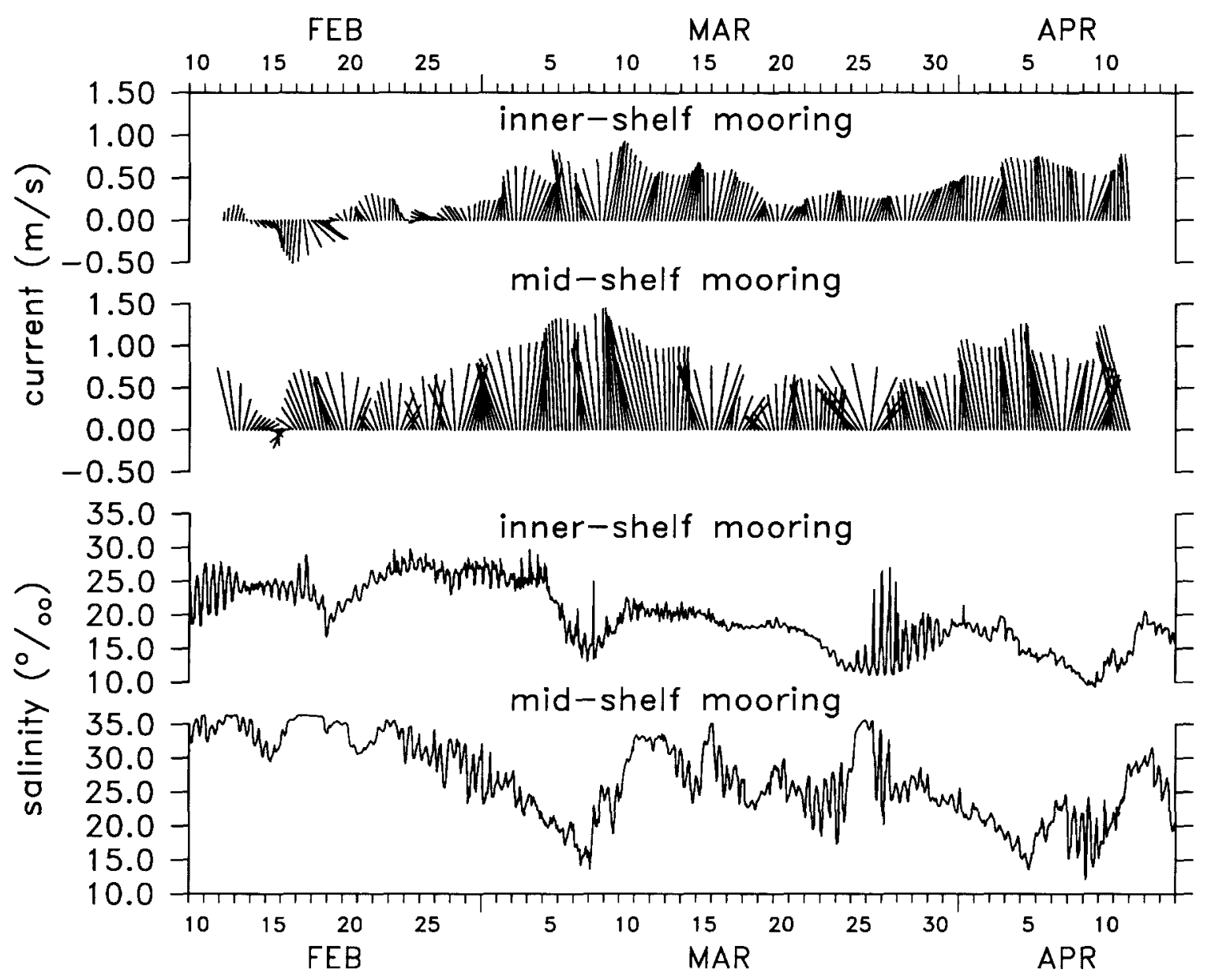

Fig. 6: Time series of current vectors and salinities measured at $3 \mathrm{~m}$ depth at the inner-and mid-shelf mooring sites, in water depths of 17 and $61 \mathrm{~m}$, respectively. The current time series are plotted with the along-shelf (northwestward) direction vertical and have been low-passed filtered to remove fluctuations with periods less than 36 hours. These measurements were made with vector averaging current meters (VACMs) inverted to locate the speed and direction sensors at $3 \mathrm{~m}$. Conductivity was measured with a SeaBird conductivity cell attached to the VACM. Despite the shallow measurement depth, the conductivity cells showed little biofouling. The current sensors failed after 2-3 months, probably due to the high current and wave velocities.

Brazil Current, local wind stress, and nonlinear tidal effects all influence the along-shelf flow and are known to vary at time scales consistent with the observed changes in velocity and salinity. The lack of correlation between the currents measured at the shelf break in the North Brazil Current to those within the Amazon plume suggests that there is no simple relationship between the fluctuations in the North Brazil Current and the variations in along-shelf transport (although the mean northwestward flow on the shelf is suspected to be related to the larger-scale oceanic flow field, perhaps through an along-shelf pressure gradient).

Variations in wind stress may explain a significant fraction of the observed along-shelf current variability, based on regression analysis between available wind data and the moored current observations. The prevailing trade winds are directed primarily onshore (southwestward) over the Amazon shelf, with speeds of 5-10 $\mathrm{m} \mathrm{s}^{-1}$ during
February through June. To monitor the winds over the shelf, the moored array included a wind recorder at the mid-shelf mooring site. While this instrument only returned a 3-week wind record, these data plus shipboard wind observations made during the hydrographic surveys show that variations in the direction of the trade winds cause the along-shelf component of wind stress to vary by $\pm 0.5 \mathrm{dyn}^{\mathrm{cm}}{ }^{-2}$. Initial analysis of these short records indicate a strong positive correlation between along-shelf wind-stress fluctuations and the near-surface currents observed in the plume. While the along-shelf wind-stress fluctuations are relatively weak, because the applied momentum flux is contained within the thin plume $(5-10 \mathrm{~m}$ thick), the resulting along-shelf velocity variations in the plume can be large.

An additional possibility is that spring-neap changes in tidal energy may actually modulate the along-shelf flow by changing the frictional drag
... there is no simple relationship between the fluctuations in the North Brazil Current and the variations in along-shelf transport... 
through changes in near-bottom turbulence and vertical stratification. The strong tidal currents and large spring-neap differential argue for marked variation in the energetics of the bottom boundary layer. There is evidence from the repeated anchor stations for spring-neap changes in vertical stratification at various parts of the Amazon shelf. Whether these changes relate to changes in the along-shelf flow is not yet known.

\section{Interdisciplinary Implications}

The physical processes operating on the Amazon shelf strongly influence the transport and fate of sediments and waterborne material on the shelf. The large fluctuations in the freshwater content and transport on the shelf suggest large changes in the residence time of Amazon River water, which may alter the transformations of chemical species and their spatial distributions. This speculation is supported by early results of the radiochemical studies in AmasSeds, which indicate anomalies in ${ }^{234} \mathrm{Th}$ and ${ }^{210} \mathrm{~Pb}$ distributions that could be explained by large temporal and spatial variations in the transport of suspended sediment and variations in shelf circulation (DeMaster et al., this issue; Nittrouer et al., this issue b). The distribution of these tracers should provide important clues as to the nature and timing of the transport between the inner shelf, where the suspended sediment concentrations are highest (Kineke et al., this issue), and the mid-shelf region of maximum sediment accumulation rate (Kuehl et al., 1986). Estimation of the net transport of the fluid muds will be difficult, in light of the observed variability of the flow field and the tremendous shears across the fluid mud layers. The determination of the transport in these dense turbid layers will be a key interdisciplinary goal of AmasSeds.

An important aspect of AmasSeds is its interdisciplinary approach. Preliminary examination of the physical observations made in AmasSeds emphasizes the need for such an approach. Not only will the highly variable physical processes discussed above influence the fate and distribution of sediment and geochemical species over the Amazon shelf, but the physical response is also modified, for example, by the presence of fluid muds in this region, which may substantially alter the bottom stress and thus modify the overlying flow.

\section{Acknowledgements}

The physical oceanographic observations described here were made as part of AmasSeds with funding from the U.S. National Science Foundation (OCE-8812917) and the Brazilian Conselho Nacional de Desenvolvimento Científico e Technologico. We want to thank the many U.S. and Brazilian scientists and technicians who helped with this effort. Woods Hole Oceanographic Institution Contribution Number 7623.
References

Curtin, T.B., 1986a: Physical observations in the plume region of the Amazon River during peak discharge-II. Water masses. Cont. Shelf Res., 6, 53-71.

1986b: Physical observations in the plume region of the Amazon River during peak discharge-III. Currents. Cont. Shelf Res., 6, 73-86.

and R.V. Legeckis, 1986: Physical observations in the plume region of the Amazon River during peak discharge-1. Surface variability. Cont. Shelf Res., 6, 3151.

DeMaster, D.J., B.A. McKee, W.S. Moore, D.M. Nelson, W.J. Showers and W.O. Smith Jr., 1991: Geochemical processes occurring in the waters at the Amazon River/ Ocean boundary. Oceanography, 4, 15-20.

E.G.\&G., 1981: Current and hydrographic measurements of the North Brazil Coastal Current between $2^{\circ}$ and $7^{\circ} \mathrm{N}$ latitude. E.G.\&G. Consultants, Waltham. MA.

Flagg. C.N., R.L. Gordon and S. McDowell, 1986: Hydrographic and current observations on the continental slope and shelf in the Western Equatorial Atlantic. Jour. Phys. Oceanogr., 16, 1412-1429.

Geyer, W.R. and D.M. Farmer, 1988: Tide induced variation of the dynamics of a salt wedge estuary. Jour. Phys Oceanogr., 28, 1060-1072.

Gibbs, R.J., 1970: Circulation in the Amazon River estuary and adjacent Atlantic Ocean. Jour. Marine Res., 28, 113-123.

1982. Currents on the shelf of Northeastern South America. Estuar. Coast. Shelf Sci., 14, 283-299.

Kineke, G.C., R.W. Sternberg, D.A. Caccione, K. Kranck and D. Drake, 1991. Distribution and characteristics of suspended sediment on the Amazon Shelf. Oceanography, 4. 21-26.

Kuehl, S.A., D.J. DeMaster, and C.A. Nittrouer, 1986: Nature of sediment accumulation on the Amazon continental shelf. Cont. Shelf Res., 6, 209-225.

Milliman, J.D.. C.P. Summerhayes and H.T. Barretto, 1975: Oceanography and suspended matter off the Amazon River February-March 1973. Jour. Sed. Petrol., 45, 189-206.

Muller-Karger, F.E., C.R. McClain and P.L. Richardson, 1988: The dispersal of the Amazon's waters. Nature, 333, 5669

Nittrouer, C.A., D.J. DeMaster, A.G. Figueiredo and J.M. Rine, 1991: AmasSeds: an interdisciplinary investigation of a complex coastal environment. Oceanography, 4. 3-7.

S.A. Kuehl, J.M. Rine, A.G. Figueiredo, L.E.C. Faria, G.T.M. Dias, M.A.M. Silva, M.A. Allison, T.D. Pacioni, M.P. Segall. E.C. Underkoffler, H.V. Borges and O.F. Silveira, 1991: Sedimentology and stratigraphy of the Amazon continental shelf. Oceanography, 4, 33-38.

NOAA, 1973: Tide Tables 1974: East Coast of North and South America. National Ocean Survey, Washington. D.C., $288 \mathrm{pp}$.

Oltman, R.E., 1968. Reconnaissance investigations of the discharge and water quality of the Amazon River. U.S. Geological Survey, Circular 552,16 pp.

Picaut, J., J. Servain, P. Lecompte, M. Seva, S. Lukas and G. Rougier, 1985: Climatic Atlas of the Tropical Atlantic Wind Stress and Sea Surface Temperature, 1964-1979. Universite de Bretagne Occidentale, $467 \mathrm{pp}$.

Richardson, P.L. and G. Reverdin, 1987; Seasonal cycle of velocity in the Atlantic North Equatorial Undercurrent as measured by surface drifters, current meters. and shipdrifts. Jour. Geophys. Res., 92, 3691-3708.

Schwiderski, E.W., 1979: Global ocean tides, Part II. The semidiurnal principal lunar tide $\left(M_{2}\right)$. In: Atlas of Tidal Charts and Maps, TR 79-414, Naval Surface Weapons Center, Dehlgren, VA, 87 pp.

Wright, L.D., 1970: Hydrography of South Pass, Mississippi River. Jour. Waterway, Port Coast. Oc. Div. 97, 491 504. $\square$ 